\title{
Convergence Theorems for Accretive Operators with Nonlinear Mappings in Banach Spaces
}

\author{
Yan-Lai Song ${ }^{1}$ and Lu-Chuan Ceng ${ }^{2}$ \\ ${ }^{1}$ Department of Mathematics, Shanghai Normal University, Shanghai 200234, China \\ ${ }^{2}$ Department of Mathematics, Shanghai Normal University and Scientific Computing Key Laboratory of Shanghai Universities, \\ Shanghai 200234, China
}

Correspondence should be addressed to Lu-Chuan Ceng; zenglc@hotmail.com

Received 4 December 2013; Accepted 17 March 2014; Published 29 April 2014

Academic Editor: Satit Saejung

Copyright ( $\odot 2014$ Y.-L. Song and L.-C. Ceng. This is an open access article distributed under the Creative Commons Attribution License, which permits unrestricted use, distribution, and reproduction in any medium, provided the original work is properly cited.

\begin{abstract}
The purpose of this paper is to present two new forward-backward splitting schemes with relaxations and errors for finding a common element of the set of solutions to the variational inclusion problem with two accretive operators and the set of fixed points of strict pseudocontractions in infinite-dimensional Banach spaces. Under mild conditions, some weak and strong convergence theorems for approximating these common elements are proved. The methods in the paper are novel and different from those in the early and recent literature. Further, we consider the problem of finding a common element of the set of solutions of a mathematical model related to equilibrium problems and the set of fixed points of a strict pseudocontractions.
\end{abstract}

\section{Introduction}

The theory of nonexpansive mappings is very important because it is applied to convex optimization, the theory of nonlinear evolution equations, and others. Browder and Petryshyn [1] introduced a class of nonlinear mappings, called strict pseudocontractions, which includes the class of nonexpansive mappings. For strict pseudocontractions, we are interested in finding fixed points of the mappings. We also know the class of inverse-strongly accretive operators which is related to nonexpansive mappings. For inverse-strongly accretive operators, we are interested in finding zero points of the mappings.

Let $C$ be a nonempty closed convex subset of a real Hilbert space $H$. Let $A: C \rightarrow H$ be a single-valued nonlinear mapping and let $B: H \rightarrow 2^{H}$ be a multivalued mapping. The so called quasi-variational inclusion problem is to find a $z \in H$ such that

$$
0 \in(A+B) z .
$$

The set of solutions of (1) is denoted by $(A+B)^{-1}(0)$. A number of problems arising in structural analysis, mechanics, and economics can be studied in the framework of this kind of variational inclusions; see, for instance, [2-5]. The problem (1) includes many problems as special cases.

(1) If $B=\partial \phi: H \rightarrow 2^{H}$, where $\phi: H \rightarrow \mathbb{R} \cup+\infty$ is a proper convex lower semicontinuous function and $\partial \phi$ is the subdifferential and if only erential of $\partial \phi$, then the variational inclusion problem (1) is equivalent to finding $u \in H$ such that

$$
\langle A u, y-u\rangle+\phi(y)-\phi(u) \geq 0, \quad \forall y \in H
$$

which is called the mixed quasi-variational inequality (see, Noor [6]).

(2) If $B=\partial \delta_{C}$, where $C$ is a nonempty closed convex subset of $H$ and $\delta_{C}: H \rightarrow[0, \infty]$ is the indicator function of $C$, that is,

$$
\delta_{C}= \begin{cases}0, & x \in C, \\ +\infty, & x \notin C,\end{cases}
$$


then the variational inclusion problem (1) is equivalent to finding $u \in C$ such that

$$
\langle A u, v-u\rangle \geq 0, \quad \forall v \in C .
$$

This problem is called Hartman-Stampacchia variational inequality (see, e.g., [7]).

In [8], Zhang et al. investigated the problem of finding a common element of the set of solutions to the inclusion problem and the set of fixed points of nonexpansive mappings by considering the following iterative algorithm:

$$
\begin{gathered}
y_{n}=J_{M, \lambda}\left(x_{n}-\lambda A x_{n}\right), \\
x_{n+1}=\alpha_{n} x+\left(1-\alpha_{n}\right) S y_{n},
\end{gathered}
$$

where $A: H \rightarrow H$ is an $\alpha$-cocoercive mapping, $M$ : $H \rightarrow 2^{H}$ is a maximal monotone mapping, $S: H \rightarrow H$ is a nonexpansive mapping, and $\left\{\alpha_{n}\right\}$ is a sequence in $[0,1]$. Under mild conditions, they obtained a strong convergence theorem.

In [9], Manaka and Takahashi introduced the following iteration:

$$
\begin{array}{r}
x_{1} \in C, \quad x_{n+1}=\alpha_{n} x_{n}+\left(1-\alpha_{n}\right) S J_{\lambda_{n}}\left(I-\lambda_{n} A\right) x_{n}, \\
n \geq 1,
\end{array}
$$

where $\left\{\alpha_{n}\right\}$ is a sequence in $(0,1),\left\{\lambda_{n}\right\}$ is a positive sequence, $S: C \rightarrow C$ is a nonexpansive mapping, $A: C \rightarrow H$ is an inverse-strongly monotone mapping, $B: D(B) \subset C \rightarrow 2^{H}$ is a maximal monotone operator, and $J_{\lambda_{n}}=\left(I+\lambda_{n} B\right)^{-1}$ is the resolvent of $B$. They showed that the sequence $\left\{x_{n}\right\}$ generated in (6) converges weakly to some $z \in(A+B)^{-1}(0) \cap F(S)$ provided that the control sequence satisfies some restrictions.

It is well known that the quasi-variational inclusion problem in the setting of Hilbert spaces has been extensively studied in the literature; see, for instance, [4-10]. However, there is little work in the existing literature on this problem in the setting of Banach spaces (though there was some work on finding a common zero of a finite family of accretive operators [11-13]). The main difficulties are due to the fact that the inner product structure of a Hilbert space fails to be true in a Banach space. To overcome these difficulties, López et al. [14] use the new technique to carry out certain initiative investigations on splitting methods for accretive operators in Banach spaces. They considered the following algorithms with errors in Banach spaces:

$$
\begin{aligned}
& x_{n+1}=\left(1-\alpha_{n}\right) x_{n}+\alpha_{n}\left(J_{r_{n}}\left(x_{n}-r_{n}\left(A x_{n}+a_{n}\right)\right)+b_{n}\right), \\
& x_{n+1}=\alpha_{n} u+\left(1-\alpha_{n}\right)\left(J_{r_{n}}\left(x_{n}-r_{n}\left(A x_{n}+a_{n}\right)\right)+b_{n}\right),
\end{aligned}
$$

where $u \in E,\left\{a_{n}\right\},\left\{b_{n}\right\} \subset E$, and $J_{r_{n}}=\left(I+r_{n} B\right)^{-1}$ is the resolvent of $B$. Then they studied the weak and strong convergence of algorithms (7) and (8), respectively.

Motivated and inspired by Zhang et al. [8], Manaka and Takahashi [9], Takahashi et al. [10], Chen and Fan [13], López et al. [14], and Cho et al. [15], the purpose of this paper is to introduce two iterative forward-backward splitting methods for finding a common element of the set of solutions of the variational inclusion problem (1) with $m$-accretive operators and inverse-strongly accretive operators and the set of fixed points of strict pseudocontractions in the setting of Banach spaces. Under suitable conditions, some weak and strong convergence theorems for approximating to these common elements are proved. The results presented in the paper improve and extend the corresponding results in $[8-10,13-$ 15].

\section{Preliminaries}

Throughout this paper, we denote by $E$ and $E^{*}$ a real Banach space and the dual space of $E$, respectively. Let $C$ be a subset of $E$ and let $T$ be a mapping on $C$. We use $F(T)$ to denote the set of fixed points of $T$. The expressions $x_{n} \rightarrow x$ and $x_{n} \rightarrow$ $x$ denote the strong and weak convergence of the sequence $\left\{x_{n}\right\}$, respectively, and $\omega_{w}\left(x_{n}\right)$ stands for the set of weak limit points of the sequence $\left\{x_{n}\right\}$. $\mathscr{B}_{r}$ will denote the closed ball with center zero and radius $r$.

Let $q>1$ be a real number. The (generalized) duality mapping $J_{q}: E \rightarrow 2^{E^{*}}$ is defined by

$$
J_{q}(x)=\left\{x^{*} \in E^{*}:\left\langle x, x^{*}\right\rangle=\|x\|^{q},\left\|x^{*}\right\|=\|x\|^{q-1}\right\}
$$

for all $x \in E$, where $\langle\cdot, \cdot\rangle$ denotes the generalized duality pairing between $E$ and $E^{*}$. In particular, $J=J_{2}$ is called the normalized duality mapping and $J_{q}(x)=\|x\|^{q-2} J_{2}(x)$ for $x \neq 0$. If $E$ is a Hilbert space, then $J=I$ where $I$ is the identity mapping. It is well known that if $E$ is smooth, then $J_{q}$ is singlevalued, which is denoted by $j_{q}$.

A Banach space $E$ is said to be uniformly convex if, for any $\varepsilon \in(0,2]$, there exists $\delta>0$ such that, for any $x, y \in$ $S(E),\|x-y\| \geq \varepsilon$ implies $\|(x+y) / 2\| \leq 1-\delta$. It is known that a uniformly convex Banach space is reflexive and strictly convex.

The norm of a Banach space $E$ is said to be Gâteaux differentiable if the limit

$$
\lim _{t \rightarrow 0} \frac{\|x+t y\|-\|x\|}{t}
$$

exists for all $x, y$ on the unit sphere $S(E)=\{x \in E:\|x\|=$ $1\}$. If, for each $y \in S(E)$, limit (10) is uniformly attained for $x \in S(E)$, then the norm of $E$ is said to be uniformly Gâteaux differentiable. The norm of $E$ is said to be Fréchet differentiable if, for each $x \in S(E)$, limit (10) is attained uniformly for $y \in S(E)$.

Let $\rho_{E}:[0,1) \rightarrow[0,1)$ be the modulus of smoothness of $E$ defined by

$$
\begin{aligned}
& \rho_{E}(t) \\
& \quad=\sup \left\{\frac{1}{2}(\|x+y\|+\|x-y\|)-1: x \in S(E),\|y\| \leq t\right\} .
\end{aligned}
$$

A Banach space $E$ is said to be uniformly smooth if $\rho_{E}(t) / t \rightarrow 0$ as $t \rightarrow 0$. Let $q>1$. A Banach space $E$ is said to be $q$-uniformly smooth, if there exists a fixed constant $c>0$ 
such that $\rho_{E}(t) \leq c t^{q}$. It is well known that $E$ is uniformly smooth if and only if the norm of $E$ is uniformly Fréchet differentiable. If $E$ is $q$-uniformly smooth, then $q \leq 2$ and $E$ is uniformly smooth, and hence the norm of $E$ is uniformly Fréchet differentiable; in particular, the norm of $E$ is Fréchet differentiable. Typical examples of both uniformly convex and uniformly smooth Banach spaces are $L^{p}$, where $p>1$. More precisely, $L^{p}$ is $\min \{p, 2\}$-uniformly smooth for every $p>1$.

A Banach space $E$ is said to satisfy Opial's condition if for any sequence $\left\{x_{n}\right\}$ in $E$ the condition that $\left\{x_{n}\right\}$ converges weakly to $x \in E$ implies that the inequality

$$
\liminf _{n \rightarrow \infty}\left\|x_{n}-x\right\|<\liminf _{n \rightarrow \infty}\left\|x_{n}-y\right\|
$$

holds for every $y \in E$ with $y \neq x$.

A Banach space $E$ is said to have the Kadec-Klee property if, for every sequence $\left\{x_{n}\right\}$ in $E, x_{n} \rightarrow x$ and $\left\|x_{n}\right\| \rightarrow\|x\|$ together imply $\left\|x_{n}-x\right\| \rightarrow 0$. As we know the duals of reflexive Banach spaces with Fréchet differentiable norms have the Kadec-Klee property.

Definition 1. A mapping T: $C \rightarrow E$ is said to be

(1) nonexpansive if

$$
\|T x-T y\| \leq\|x-y\| \quad \forall x, y \in C ;
$$

(2) $k$-Lipschitz if there exists $k>0$ such that

$$
\|T x-T y\| \leq k\|x-y\| \quad \forall x, y \in C ;
$$

in particular, if $0<k<1$, then $T$ is called contractive and if $k=1$, then $T$ reduces to a nonexpansive mapping;

(3) $\lambda$-strict pseudocontractive in the terminology of Browder and Petryshyn if for all $x, y \in C$, there exists $\lambda>0$ and $j_{q}(x-y) \in J_{q}(x-y)$ such that

$$
\begin{aligned}
& \left\langle T x-T y, j_{q}(x-y)\right\rangle \\
& \quad \leq\|x-y\|^{q}-\lambda\|(I-T) x-(I-T) y\|^{q} ;
\end{aligned}
$$

(4) accretive if for all $x, y \in C$, there exists $j_{q}(x-y) \in$ $J_{q}(x-y)$ such that

$$
\left\langle T x-T y, j_{q}(x-y)\right\rangle \geq 0
$$

(5) $\eta$-strongly accretive if for all $x, y \in C$, there exists $\eta>$ 0 and $j_{q}(x-y) \in J_{q}(x-y)$ such that

$$
\left\langle T x-T y, j_{q}(x-y)\right\rangle \geq \eta\|x-y\|^{q}
$$

(6) $\mu$-inverse-strongly accretive if for all $x, y \in C$, there exists $\mu>0$ and $j_{q}(x-y) \in J_{q}(x-y)$ such that

$$
\left\langle T x-T y, j_{q}(x-y)\right\rangle \geq \mu\|T x-T y\|^{q} .
$$

Remark 2. The conception of strict pseudocontractions was firstly introduced by Browder and Petryshyn [1] in a real Hilbert space. Let $C$ be a nonempty subset of a real Hilbert space $H$, and let $T: C \rightarrow C$ be a mapping. In light of [1], $T$ is said to be a $K$-strict pseudocontraction, if there exists a $K \in[0,1)$ such that

$$
\begin{array}{r}
\|T x-T y\|^{2} \leq\|x-y\|^{2}+K\|(I-T) x-(I-T) y\|^{2} \\
\forall x, y \in C .
\end{array}
$$

Remark 3. The class of strictly pseudocontractive mappings has been studied by several authors (see, e.g., [1, 16, 17]). However, their iterative methods are far less developed though Browder and Petryshyn [1] initiated their work in 1967. As a matter of fact, strictly pseudocontractive mappings have more powerful applications in solving inverse problems (see, e.g., [18]). Therefore it is interesting to develop the theory of iterative methods for strictly pseudocontractive mappings.

Remark 4. If $E:=H$ is a real Hilbert space, then accretive and strongly accretive operators coincide with monotone and strongly monotone operators, respectively.

Definition 5. A set-valued mapping $T: D(T) \subseteq E \rightarrow 2^{E}$ is said to be

(1) accretive if for any $x, y \in D(T)$, there exists $j(x-y) \in$ $J(x-y)$, such that for all $u \in T(x)$ and $v \in T(y)$,

$$
\langle u-v, j(x-y)\rangle \geq 0
$$

(2) $m$-accretive if $T$ is accretive and $(I+r T)(D(T))=E$ for every (equivalently, for some) $r>0$, where $I$ is the identity mapping. In real Hilbert spaces, $m$ accretive operators coincide with maximal monotone operators.

Let $M: D(M) \rightarrow 2^{E}$ be $m$-accretive. The mapping $J_{r}^{M}$ : $E \rightarrow D(M)$ defined by

$$
J_{r}^{M}(u)=(I+r M)^{-1}(u), \quad \forall u \in E,
$$

is called the resolvent operator associated with $M$, where $r$ is any positive number and $I$ is the identity mapping. It is well known that $J_{r}^{M}$ is single-valued and nonexpansive.

In order to prove our main results, we need the following lemmas.

Lemma 6 (see [19]). Let E be a Banach space and let $J_{q}$ be a generalized duality mapping. Then for any given $x, y \in E$, the following inequality holds:

$$
\begin{array}{r}
\|x+y\|^{q} \leq\|x\|^{q}+q\left\langle y, j_{q}(x+y)\right\rangle, \\
j_{q}(x+y) \in J_{q}(x+y) .
\end{array}
$$

In particular, we have, for any given $x, y \in E$,

$$
\begin{array}{r}
\|x+y\|^{2} \leq\|x\|^{2}+2\langle y, j(x+y)\rangle, \\
j(x+y) \in J(x+y) .
\end{array}
$$


Lemma 7 (see [19]). Let $1<p<\infty, q \in(1,2], r>0$ be given.

(i) If E is uniformly convex, then there exists a continuous, strictly increasing, and convex function $\varphi:[0, \infty) \rightarrow$ $[0, \infty)$ with $\varphi(0)=0$ such that

$$
\begin{array}{r}
\|\lambda x+(1-\lambda) y\|^{p} \leq \lambda\|x\|^{p}+\lambda\|y\|^{p}-W_{p}(\lambda) \varphi(\|x-y\|), \\
x, y \in \mathscr{B}_{r}, 0 \leq \lambda \leq 1,
\end{array}
$$

where $W_{p}(\lambda)=\lambda^{p}(1-\lambda)+(1-\lambda)^{p} \lambda, \mathscr{B}_{r}=\{z \in E$ : $\|z\| \leq r\}$.

(ii) If $E$ is a real q-uniformly smooth Banach space, then there exists a constant $C_{q}>0$ such that

$$
\begin{array}{r}
\|x+y\|^{q} \leq\|x\|^{q}+q\left\langle y, J_{q}(x)\right\rangle+C_{q}\|y\|^{q}, \\
\forall x, y \in E .
\end{array}
$$

Lemma 8 (see [20]). Let $\left\{a_{n}\right\},\left\{b_{n}\right\}$, and $\left\{\delta_{n}\right\}$ be sequences of nonnegative real numbers satisfying the inequality

$$
a_{n+1} \leq\left(1+\delta_{n}\right) a_{n}+b_{n}, \quad \forall n=1,2, \ldots
$$

If $\sum_{n=0}^{\infty} \delta_{n}<\infty$ and $\sum_{n=0}^{\infty} b_{n}<\infty$, then $\lim _{n \rightarrow \infty} a_{n}$ exists. In particular, $\lim _{n \rightarrow \infty} a_{n}=0$ whenever there exists a subsequence $\left\{a_{n_{k}}\right\}$ in $\left\{a_{n}\right\}$ which strongly converges to zero.

Lemma 9 (see [21]). Let $\left\{\alpha_{n}\right\}$ be a sequence of nonnegative numbers satisfying the following property:

$$
\alpha_{n+1} \leq\left(1-\gamma_{n}\right) \alpha_{n}+b_{n}+\gamma_{n} c_{n}, \quad n \in \mathbb{N},
$$

where $\left\{\gamma_{n}\right\},\left\{b_{n}\right\},\left\{c_{n}\right\}$ satisfy the restrictions

(i) $\sum_{n=1}^{\infty} \gamma_{n}=\infty$,

(ii) $b_{n} \geq 0, \sum_{n=1}^{\infty} b_{n}<\infty$,

(iii) $\limsup _{n \rightarrow \infty} c_{n} \leq 0$.

Then, $\lim _{n \rightarrow \infty} \alpha_{n}=0$.

Lemma 10 (see [16]). Let $C$ be a nonempty convex subset of a real q-uniformly smooth Banach space $E$ and let $T: C \rightarrow C$ be a $\lambda$-strict pseudocontraction. For $\alpha \in(0,1)$, we define $T_{\alpha} x=$ $(1-\alpha) x+\alpha T x$. Then, as $\alpha \in(0, \rho], \rho=\min \left\{1,\left\{q \lambda / C_{q}\right\}^{1 /(q-1)}\right\}$, $T_{\alpha}: C \rightarrow C$ is nonexpansive such that $F\left(T_{\alpha}\right)=F(T)$.

Lemma 11 (see [22]). Let $E$ be a uniformly convex Banach space, $C$ a closed convex subset of $E$, and $T: C \rightarrow E$ a nonexpansive mapping with $F(T) \neq \emptyset$. Then, $I-T$ is demiclosed at zero.

Lemma 12. Let $C$ be a nonempty closed convex subset of a real q-uniformly smooth Banach space E. Let the mapping $A$ : $C \rightarrow E$ be an $\alpha$-inverse-strongly accretive operator. Then the following inequality holds:

$$
\begin{aligned}
& \|(I-\lambda A) x-(I-\lambda A) y\|^{q} \\
& \quad \leq\|x-y\|^{q}-\lambda\left(q \alpha-C_{q} \lambda^{q-1}\right)\|A x-A y\|^{q} .
\end{aligned}
$$

In particular, if $0<\lambda \leq\left(q \alpha / C_{q}\right)^{1 /(q-1)}$, then $\|I-\lambda A\|$ is nonexpansive.

Proof. Indeed, for all $x, y \in C$, it follows from Lemma 7 that

$$
\begin{aligned}
\|(I- & \lambda A) x-(I-\lambda A) y \|^{q} \\
= & \|(x-y)-\lambda(A x-A y)\|^{q} \\
\leq & \|x-y\|^{q}-q \lambda\left\langle A x-A y, j_{q}(x-y)\right\rangle \\
& +C_{q} \lambda^{q}\|A x-A y\|^{q} \\
\leq & \|x-y\|^{q}-q \alpha \lambda\|A x-A y\|^{q} \\
& +C_{q} \lambda^{q}\|A x-A y\|^{q} \\
\leq & \|x-y\|^{q}-\lambda\left(q \alpha-C_{q} \lambda^{q-1}\right)\|A x-A y\|^{q} .
\end{aligned}
$$

It is clear that if $0<\lambda \leq\left(q \alpha / C_{q}\right)^{1 /(q-1)}$, then $I-\lambda A$ is nonexpansive. This completes the proof.

Lemma 13 (see [23]). If $E$ is a uniformly convex Banach space and $C$ is a closed convex bounded subset of $E$, there is a continuous strictly increasing function $g:[0, \infty) \rightarrow[0, \infty)$ with $g(0)=0$ such that

$$
\begin{gathered}
g(\|S(t x+(1-t) y)-(\alpha S x+(1-\alpha) S y)\|) \\
\leq\|x-y\|-\|S x-S y\|
\end{gathered}
$$

for all $x, y \in C, t \in[0,1]$ and nonexpansive mapping $S: C \rightarrow$ E.

Lemma 14 (see [24]). Let $E$ be a real reflexive Banach space such that its dual $E^{*}$ has the Kadec-Klee property. Let $\left\{x_{n}\right\}$ be a bounded sequence in $E$ and $x^{*}, y^{*} \in \omega_{w}\left(x_{n}\right)$; here $\omega_{w}\left(x_{n}\right)$ denotes the weak $w$-limit set of $\left\{x_{n}\right\}$. Suppose $\lim _{n \rightarrow \infty} \| t x_{n}+$ $(1-t) x^{*}-y^{*} \|$ exists for all $t \in[0,1]$. Then $x^{*}=y^{*}$.

Lemma 15. Assume that $E$ is a real uniformly convex and $q$ uniformly smooth Banach space. Suppose that $A: E \rightarrow E$ is $\alpha$-inverse-strongly accretive operator for some $\alpha>0$ and $B$ : $E \rightarrow 2^{E}$ is an $m$-accretive operator. Moreover, denote $J_{r}$ by

$$
J_{r} \equiv J_{r}^{B}=(I+r B)^{-1}
$$

and $T_{r}$ by

$$
T_{r}=J_{r}(I-r A)=(I+r B)^{-1}(I-r A) .
$$

Then, it holds for all $r>0$ that $F\left(T_{r}\right)=(A+B)^{-1}(0)$.

Proof. From the definition of $T_{r}$, we have

$$
\begin{aligned}
x=T_{r} x & \Longleftrightarrow x=(I+r B)^{-1}(I-r A) x \\
& \Longleftrightarrow(I-r A) x \in(I+r B) x \\
& \Longleftrightarrow 0 \in(A+B) x .
\end{aligned}
$$

This completes the proof. 
Lemma 15 alludes to the fact that, in order to solve the inclusion problem (1), it suffices to find a fixed point of $T_{r}$. Since $T_{r}$ is already split, an iterative algorithm for $T_{r}$ corresponds to a splitting algorithm for (1). However, to guarantee convergence (weak or strong) of an iterative algorithm for $T_{r}$, we need good metric properties of $T_{r}$ such as nonexpansivity. To this end, some related geometric conditions on the underlying space $E$ are very necessary (see Lemmas 16 and 17 below).

Lemma 16 (see [14]). Assume that $E$ is a real uniformly convex and q-uniformly smooth Banach space. Suppose that $A: E \rightarrow$ $E$ is $\alpha$-inverse-strongly accretive operator for some $\alpha>0$ and $B: E \rightarrow 2^{E}$ is an $m$-accretive operator. Then, the following relations hold.

(i) Given $0<s \leq r$ and $x \in E$,

$$
\begin{gathered}
\left\|T_{s} x-T_{r} x\right\| \leq\left|1-\frac{s}{r}\right|\left\|x-T_{r} x\right\|, \\
\left\|x-T_{s} x\right\| \leq 2\left\|x-T_{r} x\right\| .
\end{gathered}
$$

(ii) Given $s>0$, there exists a continuous, strictly increasing, and convex function $\phi_{q}:[0, \infty) \rightarrow[0, \infty)$ with $\phi_{q}(0)=0$ such that, for all $x, y \in \mathscr{B}_{s}$,

$$
\begin{aligned}
\left\|T_{r} x-T_{r} y\right\|^{q} \leq & \|x-y\|^{q} \\
& -r\left(\alpha q-r^{q-1} C_{q}\right)\|A x-A y\|^{q} \\
& -\phi_{q}\left(\|\left(I-J_{r}\right)(I-r A) x\right. \\
& \left.\quad-\left(I-J_{r}\right)(I-r A) y \|\right) .
\end{aligned}
$$

Lemma 17. Let $E$ be a real uniformly convex and q-uniformly smooth Banach space. Suppose that $S: E \rightarrow E$ is a nonexpansive mapping, $A: E \rightarrow E$ is an $\alpha$-inverse-strongly accretive operator for some $\alpha>0$, and $B: E \rightarrow 2^{E}$ is an $m$ accretive operator. Assume that $0<r \leq\left(q \alpha / C_{q}\right)^{1 /(q-1)}$. Then $F\left(S T_{r}\right)=F(S) \cap F\left(T_{r}\right)$.

Proof. Suppose that $x_{1} \in F\left(S T_{r}\right)$; it is sufficient to show that $x_{1} \in F(S) \cap F\left(T_{r}\right)$. Indeed, for $x_{2} \in F(S) \cap F\left(T_{r}\right)$, we have by Lemma 16 that

$$
\begin{aligned}
\left\|x_{1}-x_{2}\right\|^{q}= & \left\|S T_{r} x_{1}-S T_{r} x_{2}\right\|^{q} \\
\leq & \left\|T_{r} x_{1}-T_{r} x_{2}\right\|^{q} \\
\leq & \left\|x_{1}-x_{2}\right\|^{q} \\
& \quad-r\left(\alpha q-r^{q-1} C_{q}\right)\left\|A x_{1}-A x_{2}\right\|^{q} \\
& \quad-\phi_{q} \|\left(I-J_{r}\right)(I-r A) x_{1} \\
& \quad-\left(I-J_{r}\right)(I-r A) x_{2} \| .
\end{aligned}
$$

The property of $\phi$ and the condition $0<r \leq\left(q \alpha / C_{q}\right)^{1 /(q-1)}$ together imply that

$$
\begin{aligned}
& \left\|A x_{1}-A x_{2}\right\| \\
& \quad=\left\|\left(I-J_{r}\right)(I-r A) x_{1}-\left(I-J_{r}\right)(I-r A) x_{2}\right\|=0 .
\end{aligned}
$$

It turns out that

$$
\left\|x_{1}-T_{r} x_{1}-x_{2}+T_{r} x_{2}\right\|=0,
$$

which imply

$$
T_{r} x_{1}=x_{1} .
$$

Noticing the assumption of $x_{1}=S T_{r} x_{1}$, we can deduce $x_{1}=$ $S x_{1}$. This means that $x_{1} \in F(S) \cap F\left(T_{r}\right)$.

Lemma 18 (see [25]). Let $C$ be a nonempty, closed, and convex subset of a real q-uniformly smooth Banach space E. Let $V$ : $C \rightarrow E$ be a k-Lipschitz and $\eta$-strongly accretive operator with constants $k, \eta>0$. Let $0<\mu<\left(q \eta / C_{q} k^{q}\right)^{1 /(q-1)}$ and $\tau=$ $\mu\left(\eta-\left(C_{q} \mu^{q-1} k^{q} / q\right)\right)$. Then fort $\in(0, \min \{1,1 / \tau\})$, the mapping $S: C \rightarrow$ E defined by $S:=(I-t \mu V)$ is a contraction with a constant $1-t \tau$.

Next we give a weak convergence theorem in a Banach space $E$.

\section{Main Results}

Theorem 19. Let $E$ be a uniformly convex and q-uniformly smooth Banach space. Let $A: E \rightarrow E$ be $\alpha$-inverse-strongly accretive, $B: E \rightarrow 2^{E}$ m-accretive, and $S: E \rightarrow E \lambda$-strict pseudocontractive. Assume that $F(S) \cap(A+B)^{-1}(0) \neq \emptyset$. Define a mapping $T x:=(1-\sigma) x+\sigma S x$ for all $x \in E$. For arbitrarily given $x_{1} \in E$ and $\sigma \in(0, \rho]$, where $\rho=\min \left\{1,\left\{q \lambda / C_{q}\right\}^{1 /(q-1)}\right\}$, let $\left\{x_{n}\right\}$ be the sequence generated iteratively by

$$
\begin{array}{r}
x_{n+1}=\left(1-\alpha_{n}\right) x_{n}+\alpha_{n} T\left(J_{r_{n}}\left(x_{n}-r_{n}\left(A x_{n}+a_{n}\right)\right)+b_{n}\right), \\
\forall n \geq 1,
\end{array}
$$

where $J_{r_{n}}=\left(I+r_{n} B\right)^{-1},\left\{a_{n}\right\},\left\{b_{n}\right\} \subset E,\left\{\alpha_{n}\right\} \subset(0,1]$, and $\left\{r_{n}\right\} \subset(0,+\infty)$. Assume that

(i) $\sum_{n=1}^{\infty}\left\|a_{n}\right\|<\infty$ and $\sum_{n=1}^{\infty}\left\|b_{n}\right\|<\infty$,

(ii) $0<\liminf _{n \rightarrow \infty} \alpha_{n} \leq \lim \sup _{n \rightarrow \infty} \alpha_{n}<1$,

(iii) $0<\liminf _{n \rightarrow \infty} r_{n} \leq \limsup _{n \rightarrow \infty} r_{n}<\left(q \alpha / C_{q}\right)^{1 /(q-1)}$.

Then $\left\{x_{n}\right\}$ converges weakly to some point $x \in F(S) \cap(A+$ $B)^{-1}(0)$.

Proof. We divide the proof into several steps.

Step 1. We prove $\lim _{n \rightarrow \infty}\left\|x_{n}-z\right\|$ exists for any point $z \in$ $F(S) \cap(A+B)^{-1}(0)$.

Putting $T_{n}=J_{r_{n}}\left(I-r_{n} A\right)=\left(I+r_{n} B\right)^{-1}\left(I-r_{n} A\right)$, one has

$$
T\left(J_{r_{n}}\left(x_{n}-r_{n}\left(A x_{n}+a_{n}\right)\right)+b_{n}\right)=T T_{n} x_{n}+g_{n},
$$

where

$$
g_{n}=T\left(J_{r_{n}}\left(x_{n}-r_{n}\left(A x_{n}+a_{n}\right)\right)+b_{n}\right)-T T_{n} x_{n} .
$$


Then the iterative formula (40) turns into the form

$$
x_{n+1}=\left(1-\alpha_{n}\right) x_{n}+\alpha_{n}\left(T T_{n} x_{n}+g_{n}\right) .
$$

Thus, by virtue of Lemmas 10 and 12 and nonexpansivity of $J_{r_{n}}$, we have

$$
\begin{aligned}
\left\|g_{n}\right\| & =\left\|T\left(J_{r_{n}}\left(x_{n}-r_{n}\left(A x_{n}+a_{n}\right)\right)+b_{n}\right)-T T_{n} x_{n}\right\| \\
& \leq\left\|J_{r_{n}}\left(x_{n}-r_{n}\left(A x_{n}+a_{n}\right)\right)-T_{n} x_{n}\right\|+\left\|b_{n}\right\| \\
& \leq r_{n}\left\|a_{n}\right\|+\left\|b_{n}\right\| .
\end{aligned}
$$

By (44) and condition (i), we have that

$$
\sum_{n=1}^{\infty}\left\|g_{n}\right\|<\infty .
$$

Since $z \in F(S) \cap(A+B)^{-1}(0)$, according to Lemmas 10 and 15 , we can deduce $z \in F(T) \cap F\left(T_{n}\right)$. Lemma 16 and condition (iii) together imply $T_{n}$ is nonexpansive. Therefore, we get from (43) that

$$
\begin{aligned}
& \left\|x_{n+1}-z\right\| \\
& \quad=\left(1-\alpha_{n}\right)\left\|x_{n}-z\right\|+\alpha_{n}\left\|T T_{n} x_{n}+g_{n}-z\right\| \\
& \quad \leq\left(1-\alpha_{n}\right)\left\|x_{n}-z\right\|+\alpha_{n}\left\|T T_{n} x_{n}-z\right\|+\alpha_{n}\left\|g_{n}\right\| \\
& \quad \leq\left(1-\alpha_{n}\right)\left\|x_{n}-z\right\|+\alpha_{n}\left\|x_{n}-z\right\|+\alpha_{n}\left\|g_{n}\right\| \\
& \quad \leq\left\|x_{n}-z\right\|+\alpha_{n}\left\|g_{n}\right\| .
\end{aligned}
$$

In view of (45), (46), and Lemma 8 , we get that $\lim _{n \rightarrow \infty} \| x_{n}-$ $z \|$ exists. Therefore $\left\{x_{n}\right\}$ is bounded.

Step 2. We show $\lim _{n \rightarrow \infty}\left\|T_{n} x_{n}-x_{n}\right\|=0$.

Let $M_{1}>0$ be such that $\left\|x_{n}\right\|<M_{1}$, for all $n \in \mathbb{N}$ and let $s=q\left(M_{1}+\|z\|\right)^{q-1}$. By (43), Lemmas 6, 10, and 16, we have

$$
\begin{aligned}
&\left\|x_{n+1}-z\right\|^{q} \\
&=\left\|\left(1-\alpha_{n}\right)\left(x_{n}-z\right)+\alpha_{n}\left(T T_{n} x_{n}+g_{n}-z\right)\right\|^{q} \\
& \leq\left\|\left(1-\alpha_{n}\right)\left(x_{n}-z\right)+\alpha_{n}\left(T T_{n} x_{n}-z\right)\right\|^{q} \\
&+\alpha_{n} q\left\langle g_{n}, j_{q}\left(x_{n+1}-z\right)\right\rangle \\
& \leq\left(1-\alpha_{n}\right)\left\|x_{n}-z\right\|^{q} \\
&+\alpha_{n}\left\|T T_{n} x_{n}-z\right\|^{q}+\alpha_{n} q\left\|g_{n}\right\|\left\|x_{n+1}-z\right\|^{q-1} \\
& \leq\left(1-\alpha_{n}\right)\left\|x_{n}-z\right\|^{q}+\alpha_{n}\left\|T_{n} x_{n}-z\right\|^{q} \\
&+\alpha_{n} q\left\|g_{n}\right\|\left\|x_{n+1}-z\right\|^{q-1} \\
& \leq\left\|x_{n}-z\right\|^{q}-\alpha_{n} r_{n}\left(\alpha q-r_{n}^{q-1} C_{q}\right)\left\|A x_{n}-A z\right\|^{q} \\
&-\alpha_{n} \phi_{q}\left(\left\|\left(I-J_{r_{n}}\right)\left(I-r_{n} A\right) x_{n}-\left(I-J_{r_{n}}\right)\left(I-r_{n} A\right) z\right\|\right) \\
&+\alpha_{n} s\left\|g_{n}\right\|
\end{aligned}
$$

$$
\begin{aligned}
\leq & \left\|x_{n}-z\right\|^{q}-\alpha_{n} r_{n}\left(\alpha q-r_{n}^{q-1} C_{q}\right)\left\|A x_{n}-A z\right\|^{q} \\
& -\alpha_{n} \phi_{q}\left(\left\|x_{n}-r_{n} A x_{n}-T_{n} x_{n}+r_{n} A z\right\|\right) \\
& +\alpha_{n} s\left\|g_{n}\right\| .
\end{aligned}
$$

Meanwhile, by the fact that $a^{r}-b^{r} \leq r a^{r-1}(a-b), \forall r \geq 1$ and (47), we get that

$$
\begin{aligned}
\alpha_{n} r_{n} & \left(\alpha q-r_{n}^{q-1} C_{q}\right)\left\|A x_{n}-A z\right\|^{q} \\
& +\alpha_{n} \phi_{q}\left(\left\|x_{n}-r_{n} A x_{n}-T_{n} x_{n}+r_{n} A z\right\|\right) \\
\leq & \left\|x_{n}-z\right\|^{q}-\left\|x_{n+1}-z\right\|^{q}+\alpha_{n} s\left\|g_{n}\right\| \\
\leq & q\left\|x_{n}-z\right\|^{q-1}\left(\left\|x_{n}-z\right\|-\left\|x_{n+1}-z\right\|\right)+\alpha_{n} s\left\|g_{n}\right\| .
\end{aligned}
$$

Thanks to (45), existence of $\lim _{n \rightarrow \infty}\left\|x_{n}-z\right\|$, (ii) and (iii), one has

$$
\lim _{n \rightarrow \infty}\left\|A x_{n}-A z\right\|=\lim _{n \rightarrow \infty}\left\|x_{n}-r_{n} A x_{n}-T_{n} x_{n}+r_{n} A z\right\|=0 .
$$

It turns out that

$$
\lim _{n \rightarrow \infty}\left\|T_{n} x_{n}-x_{n}\right\|=0
$$

Step 3. We prove $\lim _{n \rightarrow \infty}\left\|T T_{n} x_{n}-x_{n}\right\|=0$.

Noticing (45) and Lemma 7, we have

$$
\begin{aligned}
\| x_{n+1} & -z \|^{2} \\
= & \left\|\left(1-\alpha_{n}\right)\left(x_{n}-z\right)+\alpha_{n}\left(T T_{n} x_{n}+g_{n}-z\right)\right\|^{2} \\
\leq & \left(1-\alpha_{n}\right)\left\|x_{n}-z\right\|^{2}+\alpha_{n}\left\|T T_{n} x_{n}+g_{n}-z\right\|^{2} \\
& -W_{2}\left(\alpha_{n}\right) \varphi\left(\left\|T T_{n} x_{n}+g_{n}-x_{n}\right\|\right) \\
\leq & \left(1-\alpha_{n}\right)\left\|x_{n}-z\right\|^{2} \\
& +\alpha_{n}\left(\left\|T T_{n} x_{n}-z\right\|^{2}+2\left\|T T_{n} x_{n}-z\right\|\left\|g_{n}\right\|+\left\|g_{n}\right\|^{2}\right) \\
& -W_{2}\left(\alpha_{n}\right) \varphi\left(\left\|T T_{n} x_{n}+g_{n}-x_{n}\right\|\right) \\
\leq & \left(1-\alpha_{n}\right)\left\|x_{n}-z\right\|^{2} \\
& +\alpha_{n}\left(\left\|x_{n}-z\right\|^{2}+2\left\|x_{n}-z\right\|\left\|g_{n}\right\|+\left\|g_{n}\right\|^{2}\right) \\
& -W_{2}\left(\alpha_{n}\right) \varphi\left(\left\|T T_{n} x_{n}+g_{n}-x_{n}\right\|\right) \\
\leq & \left\|x_{n}-z\right\|^{2}+2 \alpha_{n}\left\|x_{n}-z\right\|\left\|g_{n}\right\|+\alpha_{n}\left\|g_{n}\right\|^{2} \\
& -W_{2}\left(\alpha_{n}\right) \varphi\left(\left\|T T_{n} x_{n}+g_{n}-x_{n}\right\|\right) \\
\leq & \left\|x_{n}-z\right\|^{2}+2\left\|x_{n}-z\right\|\left\|g_{n}\right\|+\left\|g_{n}\right\|^{2} \\
& -W_{2}\left(\alpha_{n}\right) \varphi\left(\left\|T T_{n} x_{n}+g_{n}-x_{n}\right\|\right),
\end{aligned}
$$


which implies

$$
\begin{gathered}
W_{2}\left(\alpha_{n}\right) \varphi\left(\left\|T T_{n} x_{n}+g_{n}-x_{n}\right\|\right) \\
\leq\left\|x_{n}-z\right\|^{2}-\left\|x_{n+1}-z\right\|^{2} \\
\quad+2\left\|x_{n}-z\right\|\left\|g_{n}\right\|+\left\|g_{n}\right\|^{2},
\end{gathered}
$$

where $W_{2}\left(\alpha_{n}\right)=\alpha_{n}\left(1-\alpha_{n}\right)$. From (45), (52), (ii), and existence of $\lim _{n \rightarrow \infty}\left\|x_{n}-z\right\|$, it turns out that

$$
\lim _{n \rightarrow \infty} \varphi\left(\left\|T T_{n} x_{n}+g_{n}-x_{n}\right\|\right)=0 \text {. }
$$

It follows from the property of $\varphi$ and (45) that

$$
\lim _{n \rightarrow \infty}\left\|T T_{n} x_{n}-x_{n}\right\|=0 \text {. }
$$

Step 4. We prove $\omega_{w}\left(x_{n}\right) \subset F(S) \cap(A+B)^{-1}(0)$.

Since $0<\liminf _{n \rightarrow \infty} r_{n} \leq \limsup _{n \rightarrow \infty} r_{n}<1$, there exists $\varepsilon>0$ such that $r_{n} \geq \varepsilon$ for all $n \geq 1$. Then, by Lemma 16, we have

$$
\lim _{n \rightarrow \infty}\left\|T_{\varepsilon} x_{n}-x_{n}\right\| \leq 2 \lim _{n \rightarrow \infty}\left\|T_{n} x_{n}-x_{n}\right\|=0 .
$$

It follows from (50), (54), and (55) that

$$
\begin{aligned}
& \left\|T T_{\varepsilon} x_{n}-x_{n}\right\| \\
& \quad \leq\left\|T T_{\varepsilon} x_{n}-T T_{n} x_{n}\right\|+\left\|T T_{n} x_{n}-x_{n}\right\| \\
& \quad \leq\left\|T_{\varepsilon} x_{n}-T_{n} x_{n}\right\|+\left\|T T_{n} x_{n}-x_{n}\right\| \\
& \quad \leq\left\|T_{\varepsilon} x_{n}-x_{n}\right\|+\left\|x_{n}-T_{n} x_{n}\right\|+\left\|T T_{n} x_{n}-x_{n}\right\| \\
& \quad \longrightarrow 0 .
\end{aligned}
$$

By Lemmas 10, 11, and 17 and (56), we get

$$
\begin{aligned}
\omega_{w}\left(x_{n}\right) \subset F\left(T T_{\varepsilon}\right) & =F(T) \cap F\left(T_{\varepsilon}\right) \\
& =F(S) \cap(A+B)^{-1}(0) .
\end{aligned}
$$

Step 5. We show $\left\{x_{n}\right\}$ converges weakly to a fixed point of $x \in$ $F(S) \cap(A+B)^{-1}(0)$.

Indeed, it suffices to show $\omega_{w}\left(x_{n}\right)$ consists of exactly only one point. To this end, we suppose that two different points $x$ and $y$ are in $\omega_{w}\left(x_{n}\right)$. Then there exist two different subsequences $\left\{n_{i}\right\}$ and $\left\{n_{j}\right\}$ such that $x_{n_{i}} \rightarrow x$ and $x_{n_{j}} \rightarrow y$ as $i \rightarrow \infty$ and $j \rightarrow \infty$. Define $S_{n, m}: E \rightarrow E$ by

$$
\begin{gathered}
S_{n, m}=V_{n+m-1} V_{n+m-2} \cdots V_{n}, \\
V_{n}=\left(1-\alpha_{n}\right) I+\alpha_{n} T T_{n} .
\end{gathered}
$$

Then $x_{n}$ can be written

$$
x_{n+m}=S_{n, m} x_{n}+c_{n, m},
$$

where

$$
\begin{aligned}
c_{n, m}= & V_{n+m-1} \\
& \times\left(V_{n+m-2}\left(\cdots V_{n+1}\left(V_{n} x_{n}+\alpha_{n} g_{n}\right)+\alpha_{n+1} g_{n+1} \cdots\right)\right. \\
& \left.\quad+\alpha_{n+m-2} g_{n+m-2}\right) \\
& +\alpha_{n+m-1} g_{n+m-1}-S_{n, m} x_{n} .
\end{aligned}
$$

Thanks to the nonexpansivity of $V_{n}$, we have

$$
\left\|c_{n, m}\right\| \leq \sum_{k=n}^{n+m-1}\left\|\alpha_{k} g_{k}\right\| \leq \sum_{k=n}^{n+m-1}\left\|g_{k}\right\|
$$

It follows from (45) that

$$
\lim _{m, n \rightarrow \infty}\left\|c_{n, m}\right\| \longrightarrow 0 .
$$

Let

$$
\begin{gathered}
f_{n}(t)=\left\|t x_{n}+(1-t) x-y\right\|, \\
d_{n, m}=S_{n, m}\left(t x_{n}+(1-t) x\right)-\left(t S_{n, m} x_{n}+(1-t) x\right) .
\end{gathered}
$$

Applying Lemma 13 to the closed convex bounded subset $D:=\overline{\mathrm{co}}\left(\left\{x_{n}\right\} \cup\{x, y\}\right)$, we obtain

$$
\begin{aligned}
g\left(\left\|d_{n, m}\right\|\right) & \leq\left\|x_{n}-x\right\|-\left\|S_{n, m} x_{n}-S_{n, m} x\right\| \\
& \leq\left\|x_{n}-x\right\|-\left\|x_{n+m}-x-c_{n, m}\right\| \\
& \leq\left\|x_{n}-x\right\|-\left\|x_{n+m}-x\right\|+\left\|c_{n, m}\right\| .
\end{aligned}
$$

Since $\lim _{n \rightarrow \infty}\left\|x_{n}-x\right\|$ exists, (62), (64), and the property of $g$ together imply that

$$
\lim _{m, n \rightarrow \infty}\left\|d_{n, m}\right\| \longrightarrow 0
$$

Furthermore, we have

$$
\begin{aligned}
f_{n+m}(t) & =\left\|t x_{n+m}+(1-t) x-y\right\| \\
& \leq\left\|d_{n, m}\right\|+\left\|S_{n, m}\left(t x_{n}+(1-t) x\right)-y\right\|+t\left\|c_{m, n}\right\| \\
& \leq\left\|d_{n, m}\right\|+\left\|t x_{n}+(1-t) x-y\right\|+t\left\|c_{m, n}\right\| \\
& =\left\|d_{n, m}\right\|+f_{n}(t)+t\left\|c_{m, n}\right\| .
\end{aligned}
$$

After taking first $\limsup _{m \rightarrow \infty}$ and then $\liminf _{n \rightarrow \infty}$ in (66) and using (62) and (65), we get

$$
\begin{aligned}
\limsup _{m \rightarrow \infty} f_{m}(t) \leq & \liminf _{n \rightarrow \infty} f_{n}(t) \\
& +\lim _{m, n \rightarrow \infty}\left(\left\|d_{m, n}\right\|+\left\|c_{n, m}\right\|\right)=\liminf _{n \rightarrow \infty} f_{n}(t) .
\end{aligned}
$$

So $\lim _{n \rightarrow \infty}\left\|t x_{n}+(1-t) x-y\right\|$ exists for all $t \in[0,1]$. It follows from Lemma 14 that $x=y$. This completes the proof.

Remark 20. Compared with the known results in the literature, our results are very different from those in the following aspects.

(i) Theorem 19 improves and extends Theorem 3 of Kamimura and Takahashi [4] and Theorem 3.1 of Manaka and Takahashi [9] from Hilbert spaces to uniformly convex and $q$-uniformly smooth Banach spaces. 
(ii) Theorem 19 also improves and extends Theorem 3.6 of López et al. [14] from the problem of finding an element of $(A+B)^{-1}(0)$ to the problem of finding an element of $(A+B)^{-1}(0) \cap F(S)$, where $S$ is $\lambda$-strictly pseudocontractive on $E$.

In the following, we give a strong convergence theorem in a Banach space $E$.

Theorem 21. Let $E$ be a uniformly convex and q-uniformly smooth Banach space which admits a weakly sequentially continuous generalized duality mapping $j_{q}: E \rightarrow E^{*}$. Let $A: E \rightarrow E$ be $\alpha$-inverse-strongly accretive, $B: E \rightarrow 2^{E} m$ accretive, $G: E \rightarrow E k$-Lipschitz and $\eta$-strongly accretive, $\psi: E \rightarrow E$ L-Lipschitz, and $S: E \rightarrow E \lambda$-strictly pseudocontractive. Define a mapping $T x:=(1-\sigma) x+\sigma S x$ for all $x \in E$. For arbitrarily given $x_{1} \in E$ and $\sigma \in(0, \rho]$, where $\rho=\min \left\{1,\left\{q \lambda / C_{q}\right\}^{1 /(q-1)}\right\}$, let $\left\{x_{n}\right\}$ be the sequence generated iteratively by

$$
\begin{aligned}
x_{n+1}= & \alpha_{n} \gamma \psi\left(x_{n}\right)+\left(I-\alpha_{n} \mu G\right) T \\
& \times\left(J_{r_{n}}\left(x_{n}-r_{n}\left(A x_{n}+a_{n}\right)\right)+b_{n}\right), \quad \forall n \geq 1 .
\end{aligned}
$$

Assume that $\left\{\alpha_{n}\right\} \subset[0,1],\left\{r_{n}\right\} \subset(0,+\infty)$ and $\left\{a_{n}\right\},\left\{b_{n}\right\} \subset E$ satisfying the following conditions:

(i) $\sum_{n=1}^{\infty}\left\|a_{n}\right\|<\infty$ and $\sum_{n=1}^{\infty}\left\|b_{n}\right\|<\infty$,

(ii) $\sum_{n=1}^{\infty} \alpha_{n}=\infty, \lim _{n \rightarrow \infty} \alpha_{n}=0$ and $\sum_{n=1}^{\infty}\left|\alpha_{n+1}-\alpha_{n}\right|<$ $\infty$,

(iii) $0<\liminf _{n \rightarrow \infty} r_{n} \leq \limsup _{n \rightarrow \infty} r_{n}<\left(q \alpha / C_{q}\right)^{1 /(q-1)}$ and $\sum_{n=1}^{\infty}\left|r_{n+1}-r_{n}\right|<\infty$.

Suppose in addition that $(S) \cap(A+B)^{-1}(0) \neq \emptyset, 0<\mu<$ $\left(q \eta / C_{q} k^{q}\right)^{1 /(q-1)}$ and $0 \leq \gamma L<\tau$, where $\tau=\mu(\eta-$ $\left.\left(C_{q} \mu^{q-1} k^{q} / q\right)\right)$. Then $\left\{x_{n}\right\}$ converges strongly to some point $z \in$ $F(S) \cap(A+B)^{-1}(0)$ which solves the variational inequality: $\left\langle\gamma \psi(z)-\mu G(z), j_{q}(x-z)\right\rangle \leq 0$, for all $x \in F(S) \cap(A+B)^{-1}(0)$.

Proof. Let $\left\{y_{n}\right\}$ be a sequence generated by

$$
y_{n+1}=\alpha_{n} \gamma \psi\left(y_{n}\right)+\left(I-\alpha_{n} \mu G\right) T T_{n} y_{n}
$$

where $T_{n}:=J_{r_{n}}\left(I-r_{n} A\right)$. We show $\left\|y_{n}-x_{n}\right\| \rightarrow 0$.

It follows from Lemmas 10,12 , and 18 that

$$
\begin{aligned}
& \left\|y_{n+1}-x_{n+1}\right\| \\
& \leq \| \alpha_{n} \gamma \psi\left(y_{n}\right)+\left(I-\alpha_{n} \mu G\right) T J_{r_{n}}\left(y_{n}-r_{n} A y_{n}\right) \\
& \quad-\alpha_{n} \gamma \psi\left(x_{n}\right)-\left(I-\alpha_{n} \mu G\right) T \\
& \quad \times\left(J_{r_{n}}\left(x_{n}-r_{n}\left(A x_{n}+a_{n}\right)\right)+b_{n}\right) \|
\end{aligned}
$$

$$
\begin{aligned}
& \leq\left(1-\alpha_{n} \tau\right) \| T J_{r_{n}}\left(y_{n}-r_{n} A y_{n}\right) \\
& \quad-T\left(J_{r_{n}}\left(x_{n}-r_{n}\left(A x_{n}+a_{n}\right)\right)+b_{n}\right) \| \\
& \quad+\alpha_{n} \gamma L\left\|y_{n}-x_{n}\right\| \\
& \leq\left(1-\alpha_{n} \tau\right) \| J_{r_{n}}\left(y_{n}-r_{n} A y_{n}\right) \\
& \quad-J_{r_{n}}\left(x_{n}-r_{n}\left(A x_{n}+a_{n}\right)\right) \| \\
& \quad+\left\|b_{n}\right\|+\alpha_{n} \gamma L\left\|y_{n}-x_{n}\right\| \\
& \leq\left[1-\alpha_{n}(\tau-\gamma L)\right]\left\|y_{n}-x_{n}\right\| \\
& \quad+r_{n}\left\|a_{n}\right\|+\left\|b_{n}\right\| .
\end{aligned}
$$

By virtue of Lemma 8, (i), and (70), we have $\lim _{n \rightarrow \infty} \| y_{n}-$ $x_{n} \|=0$.

Hence, to show the desired result, it suffices to prove that $y_{n} \rightarrow z$.

Step 1. We prove that the sequence $\left\{y_{n}\right\}$ is bounded. Taking $x \in F(S) \cap(A+B)^{-1}(0)$, it follows from Lemmas 10, 12, 15, and 16 and condition (iii) that

$$
\begin{aligned}
\left\|y_{n+1}-x\right\|= & \left\|\alpha_{n} \gamma \psi\left(y_{n}\right)+\left(I-\alpha_{n} \mu G\right) T T_{n} y_{n}-x\right\| \\
= & \| \alpha_{n} \gamma\left(\psi\left(y_{n}\right)-\psi(x)\right)+\alpha_{n}(\gamma \psi(x)-\mu G(x)) \\
& +\left(I-\alpha_{n} \mu G\right) T T_{n} y_{n}-\left(I-\alpha_{n} \mu G\right) x \| \\
\leq & \alpha_{n} \gamma L\left\|y_{n}-x\right\|+\alpha_{n}\|\gamma \psi(x)-\mu G(x)\| \\
& +\left(1-\alpha_{n} \tau\right)\left\|y_{n}-x\right\| \\
= & {\left[1-\alpha_{n}(\tau-\gamma L)\right]\left\|y_{n}-x\right\| } \\
& +\alpha_{n}\|\gamma \psi(x)-\mu G(x)\| \\
\leq & \max \left\{\frac{\|\gamma \psi(x)-\mu G(x)\|}{\tau-\gamma L},\left\|y_{n}-x\right\|\right\} .
\end{aligned}
$$

By induction, we have

$$
\left\|y_{n}-x\right\| \leq \max \left\{\frac{\|\gamma \psi(x)-\mu G(x)\|}{\tau-\gamma L},\left\|y_{1}-x\right\|\right\}, \quad \forall n \geq 1 .
$$

Hence, $\left\{y_{n}\right\}$ is bounded, and so are $\left\{\psi\left(y_{n}\right)\right\}$ and $\left\{T_{n}\left(y_{n}\right)\right\}$.

Step 2. We prove that

$$
\lim _{n \rightarrow \infty}\left\|y_{n+1}-y_{n}\right\| \longrightarrow 0 .
$$

Putting $z_{n}=T_{n} y_{n}=J_{r_{n}}\left(I-r_{n} A\right) y_{n}$, it follows from Lemma 16 that

$$
\begin{aligned}
& \left\|z_{n+1}-z_{n}\right\| \\
& \quad=\left\|T_{n+1} y_{n+1}-T_{n} y_{n}\right\| \\
& \quad \leq\left\|T_{n+1} y_{n+1}-T_{n} y_{n+1}\right\|+\left\|T_{n} y_{n+1}-T_{n} y_{n}\right\|
\end{aligned}
$$




$$
\begin{aligned}
& \leq\left|1-\frac{r_{\alpha_{n}}}{r_{\beta_{n}}}\right|\left\|y_{n+1}-J_{r_{\beta_{n}}}\left(1-r_{\beta_{n}} A\right) y_{n+1}\right\|+\left\|y_{n+1}-y_{n}\right\| \\
& \leq\left|r_{\beta_{n}}-r_{\alpha_{n}}\right| \frac{\left\|y_{n+1}-J_{r_{\beta_{n}}}\left(1-r_{\beta_{n}} A\right) y_{n+1}\right\|}{r_{\beta_{n}}}+\left\|y_{n+1}-y_{n}\right\| \\
& \leq\left|r_{n+1}-r_{n}\right| M_{2}+\left\|y_{n+1}-y_{n}\right\|,
\end{aligned}
$$

where $M_{2}>\sup _{n \geq 1}\left\{\left\|y_{n+1}-J_{r_{\beta_{n}}}\left(1-r_{\beta_{n}} A\right) y_{n+1}\right\| / r_{\beta_{n}}\right\}, r_{\alpha_{n}}=$ $\min \left\{r_{n+1}, r_{n}\right\}$, and $r_{\beta_{n}}=\max \left\{r_{n+1}, r_{n}\right\}$. Hence from (69) and (74) we have

$$
\begin{aligned}
&\left\|y_{n+1}-y_{n}\right\| \\
&=\| \alpha_{n} \gamma \psi\left(y_{n}\right)+\left(I-\alpha_{n} \mu G\right) T z_{n} \\
& \quad-\alpha_{n-1} \gamma \psi\left(y_{n-1}\right)-\left(I-\alpha_{n-1} \mu G\right) T z_{n-1} \| \\
&=\| \alpha_{n} \gamma\left(\psi\left(y_{n}\right)-\psi\left(y_{n-1}\right)\right)+\left(I-\alpha_{n} \mu G\right) T z_{n} \\
& \quad-\left(I-\alpha_{n} \mu G\right) T z_{n-1}+\left(\alpha_{n}-\alpha_{n-1}\right) \\
& \quad \times\left(\gamma \psi\left(y_{n-1}\right)-\mu G T z_{n-1}\right) \| \\
& \leq\left(1-\alpha_{n} \tau\right)\left\|T z_{n}-T z_{n-1}\right\| \\
&+\alpha_{n} \gamma L\left\|y_{n}-y_{n-1}\right\|+\left|\alpha_{n}-\alpha_{n-1}\right| M_{3} \\
& \leq\left(1-\alpha_{n} \tau\right)\left\|z_{n}-z_{n-1}\right\| \\
&+\alpha_{n} \gamma L\left\|y_{n}-y_{n-1}\right\|+\left|\alpha_{n}-\alpha_{n-1}\right| M_{3} \\
& \leq {\left[1-\alpha_{n}(\tau-\gamma L)\right]\left\|y_{n}-y_{n-1}\right\| } \\
&+\left|\alpha_{n}-\alpha_{n-1}\right| M_{3}+\left|r_{n}-r_{n-1}\right| M_{2},
\end{aligned}
$$

where $M_{3}>\sup _{n \geq 1}\left\{\left\|\gamma \psi\left(y_{n}\right)-\mu G T z_{n}\right\|\right\}$. It follows from Lemma 9, (ii), and (iii) that $\lim _{n \rightarrow \infty}\left\|y_{n+1}-y_{n}\right\|=0$. Again from Lemmas 6 and 16, we obtain

$$
\begin{aligned}
\left\|y_{n+1}-x\right\|^{q} \\
=\left\|\alpha_{n} \gamma \psi\left(y_{n}\right)+\left(I-\alpha_{n} \mu G\right) T z_{n}-x\right\|^{q} \\
=\| \alpha_{n}\left(\gamma \psi\left(y_{n}\right)-\mu G(x)\right)+\left(I-\alpha_{n} \mu G\right) T z_{n} \\
\quad \quad\left(I-\alpha_{n} \mu G\right) x \|^{q} \\
\leq \quad\left(1-\alpha_{n} \tau\right)\left\|T_{n} y_{n}-x\right\|^{q} \\
\quad+q \alpha_{n}\left\langle\gamma \psi\left(y_{n}\right)-\mu G(x), j_{q}\left(y_{n+1}-x\right)\right\rangle \\
\leq\left\|T_{n} y_{n}-x\right\|^{q}+q \alpha_{n} M_{4} \\
\leq\left\|y_{n}-x\right\|^{q}-r_{n}\left(\alpha q-r_{n}^{q-1} C_{q}\right)\left\|A y_{n}-A x\right\|^{q} \\
\quad-\phi_{q}\left(\left\|y_{n}-r_{n} A y_{n}-T_{n} y_{n}+r_{n} A x\right\|\right)+q \alpha_{n} M_{4},
\end{aligned}
$$

where $M_{4}>\sup _{n \geq 1}\left\{\left\langle\gamma \psi\left(y_{n}\right)-\mu G(x), j_{q}\left(y_{n+1}-x\right)\right\rangle\right\}$. Meanwhile, by the fact that $a^{r}-b^{r} \leq r a^{r-1}(a-b)$ for all $r \geq 1$, we get that

$$
\begin{aligned}
r_{n}\left(\alpha q-r_{n}^{q-1} C_{q}\right)\left\|A y_{n}-A x\right\|^{q} \\
\quad+\phi_{q}\left(\left\|y_{n}-r_{n} A y_{n}-T_{n} y_{n}+r_{n} A x\right\|\right) \\
\leq\left\|y_{n}-x\right\|^{q}-\left\|y_{n+1}-x\right\|^{q}+q \alpha_{n} M_{4} \\
\leq q\left\|y_{n}-x\right\|^{q-1}\left(\left\|y_{n}-x\right\|-\left\|y_{n+1}-x\right\|\right)+q \alpha_{n} M_{4} .
\end{aligned}
$$

It follows immediately from (ii), (iii), (77), existence of $\lim _{n \rightarrow \infty}\left\|y_{n}-x\right\|$, and the property of $\phi_{q}$ that

$$
\lim _{n \rightarrow \infty}\left\|A y_{n}-A x\right\|=\lim _{n \rightarrow \infty}\left\|y_{n}-r_{n} A y_{n}-T_{n} y_{n}+r_{n} A x\right\|=0 .
$$

Hence we obtain that

$$
\lim _{n \rightarrow \infty}\left\|T_{n} y_{n}-y_{n}\right\|=0 .
$$

By condition (iii), there exists $\varepsilon>0$ such that $r_{n} \geq \varepsilon$ for all $n \geq 1$. Then, by Lemma 16 , we get

$$
\lim _{n \rightarrow \infty}\left\|T_{\varepsilon} y_{n}-y_{n}\right\| \leq \lim _{n \rightarrow \infty} 2\left\|T_{n} y_{n}-y_{n}\right\|=0 .
$$

Step 3. We show $\lim _{n \rightarrow \infty}\left\|T T_{\varepsilon} y_{n}-y_{n}\right\|=0$.

From (73), (79), (80), and (ii), we have

$$
\begin{aligned}
&\left\|T T_{\varepsilon} y_{n}-y_{n}\right\| \\
& \leq\left\|T T_{\varepsilon} y_{n}-T T_{n} y_{n}\right\|+\left\|T T_{n} y_{n}-y_{n}\right\| \\
& \leq\left\|T_{\varepsilon} y_{n}-T_{n} y_{n}\right\|+\left\|T T_{n} y_{n}-y_{n}\right\| \\
& \leq\left\|T_{\varepsilon} y_{n}-y_{n}\right\|+\left\|y_{n}-T_{n} y_{n}\right\| \\
&+\left\|T T_{n} y_{n}-y_{n+1}\right\|+\left\|y_{n+1}-y_{n}\right\| \\
& \leq\left\|T_{\varepsilon} y_{n}-y_{n}\right\|+\left\|y_{n}-T_{n} y_{n}\right\| \\
&+\alpha_{n}\left\|\gamma \psi\left(y_{n}\right)-\mu G T T_{n} y_{n}\right\|+\left\|y_{n+1}-y_{n}\right\| \\
& \longrightarrow 0 .
\end{aligned}
$$

Lemmas 10, 11, and 17 and (81) together imply that

$$
\begin{aligned}
\omega_{w}\left(y_{n}\right) \subset F\left(T T_{\varepsilon}\right) & =F(T) \cap F\left(T_{\varepsilon}\right) \\
& =F(S) \cap(A+B)^{-1}(0) .
\end{aligned}
$$

By Song's Lemma 2.11 [25], we deduce directly that $\left\{z_{t}\right\}$ defined by $z_{t}=t \gamma \psi\left(z_{t}\right)-(I-t \mu G) T T_{\varepsilon} z_{t}$ converges strongly to some point $z \in F\left(T T_{\varepsilon}\right)$ which is the unique solution of the variational inequality:

$$
\left\langle\gamma \psi(z)-\mu G(z), j_{q}(x-z)\right\rangle \leq 0, \quad \forall x \in F\left(T T_{\varepsilon}\right) .
$$

Step 4 . We prove that

$$
\limsup _{n \rightarrow \infty}\left\langle\gamma \psi(z)-\mu G(z), j_{q}\left(y_{n}-z\right)\right\rangle \leq 0 .
$$


We take a subsequence $\left\{y_{n_{i}}\right\}$ of $\left\{y_{n}\right\}$ such that

$$
\begin{aligned}
\limsup _{n \rightarrow \infty} & \left\langle\gamma \psi(z)-\mu G(z), j_{q}\left(y_{n}-z\right)\right\rangle \\
= & \lim _{i \rightarrow \infty}\left\langle\gamma \psi(z)-\mu G(z), j_{q}\left(y_{n_{i}}-z\right)\right\rangle .
\end{aligned}
$$

Without loss of generality, we may further assume that $y_{n_{i}} \rightarrow$ $\tilde{x}$ due to reflexivity of the Banach space $E$ and boundness of $\left\{y_{n}\right\}$. It follows from (82) that $\tilde{x} \in F\left(T T_{\varepsilon}\right)$. Since Banach space $E$ has a weakly sequentially continuous generalized duality mapping $j_{p}: E \rightarrow E^{*}$, we obtain that

$$
\begin{aligned}
& \limsup _{n \rightarrow \infty}\left\langle\gamma \psi(z)-\mu G(z), j_{q}\left(y_{n}-z\right)\right\rangle \\
& \quad=\lim _{i \rightarrow \infty}\left\langle\gamma \psi(z)-\mu G(z), j_{q}\left(y_{n_{i}}-z\right)\right\rangle \\
& \quad=\left\langle\gamma \psi(z)-\mu G(z), j_{q}(\tilde{x}-z)\right\rangle \\
& \quad \leq 0 .
\end{aligned}
$$

Step 5. We show $\left\|y_{n}-z\right\| \rightarrow 0$.

By Lemmas 9 and 16 and the fact that $a b \leq(1 / q) a^{q}+((q-$ 1)/q) $b^{q /(q-1)}$, we get

$$
\begin{aligned}
\| y_{n+1} & -z \|^{q} \\
= & \left\|\alpha_{n} \gamma \psi\left(y_{n}\right)+\left(I-\alpha_{n} \mu G\right) T T_{n} y_{n}-z\right\|^{q} \\
= & \left\langle\alpha_{n} \gamma \psi\left(y_{n}\right)+\left(I-\alpha_{n} \mu G\right) T T_{n} y_{n}-z, j_{q}\left(y_{n+1}-z\right)\right\rangle \\
= & \alpha_{n} \gamma\left\langle\psi\left(y_{n}\right)-\psi(z), j_{q}\left(y_{n+1}-z\right)\right\rangle \\
& +\alpha_{n}\left\langle\gamma \psi(z)-\mu G(z), j_{q}\left(y_{n+1}-z\right)\right\rangle \\
& +\left\langle\left(I-\alpha_{n} \mu G\right) T T_{n} y_{n}-\left(I-\alpha_{n} \mu G\right) z, j_{q}\left(y_{n+1}-z\right)\right\rangle \\
\leq & \alpha_{n} \gamma\left\|\psi\left(y_{n}\right)-\psi(z)\right\|\left\|y_{n+1}-z\right\|^{q-1} \\
& +\alpha_{n}\left\langle\gamma \psi(z)-\mu G(z), j_{q}\left(y_{n+1}-z\right)\right\rangle \\
& +\left(1-\alpha_{n} \tau\right)\left\|y_{n}-z\right\|\left\|y_{n+1}-z\right\|^{q-1} \\
\leq & \alpha_{n} L\left\|y_{n}-z\right\|\left\|y_{n+1}-z\right\|^{q-1} \\
& +\alpha_{n}\left\langle\gamma \psi(z)-\mu G(z), j_{q}\left(y_{n+1}-z\right)\right\rangle \\
& +\left(1-\alpha_{n} \tau\right)\left\|y_{n}-z\right\|\left\|y_{n+1}-z\right\|^{q-1} \\
\leq & {\left[1-\alpha_{n}(\tau-\gamma L)\right]\left\|y_{n}-z\right\|\left\|y_{n+1}-z\right\|^{q-1} } \\
& +\alpha_{n}\left\langle\gamma \psi(z)-\mu G(z), j_{q}\left(y_{n+1}-z\right)\right\rangle \\
& {\left[1-\alpha_{n}(\tau-\gamma L)\right] \frac{1}{q}\left\|y_{n}-z\right\|^{q}+\frac{q-1}{q}\left\|y_{n+1}-z\right\|^{q} } \\
& \\
&
\end{aligned}
$$

which implies that

$$
\begin{aligned}
&\left\|y_{n+1}-z\right\|^{q} \leq {\left[1-\alpha_{n}(\tau-\gamma L)\right]\left\|y_{n}-z\right\|^{q} } \\
&+q \alpha_{n}\left\langle\gamma \psi(z)-\mu G(z), j_{q}\left(y_{n+1}-z\right)\right\rangle .
\end{aligned}
$$

Apply Lemma 9 to (88) to conclude $y_{n} \rightarrow z$ as $n \rightarrow \infty$. This completes the proof.

Remark 22. Theorem 21 improves and extends Theorem 3.7 of López et al. [14] in the following aspects:

(i) from the problem of finding an element of $(A+B)^{-1}(0)$ to the problem of finding an element of $(A+B)^{-1}(0) \cap$ $F(S)$, where $S$ is $\lambda$-strictly pseudocontractive on $E$;

(ii) from a fixed element $u$ to a Lipschitz mapping $\psi$.

Remark 23. Theorem 21 improves and extends Theorem 2.1 of Zhang et al. [8] in the following aspects:

(i) from Hilbert spaces to uniformly convex and $q$ uniformly smooth Banach spaces;

(ii) from finding a common element of the set of solutions to the variational inclusion problem and the set of fixed points of nonexpansive mappings to finding a common element of the set of solutions to the variational inclusion problem and the set of fixed points of $\lambda$-strict pseudocontractions;

(iii) from a fixed element $u$ to a Lipschitz mapping $\psi$;

(iv) from a fixed positive number $\lambda$ to a sequence positive number $\left\{r_{n}\right\}$.

As a direct consequence of Theorem 21, we obtain the following result.

Corollary 24. Let $H$ be a real Hilbert space. Let $A: H \rightarrow H$ be $\alpha$-inverse-strongly monotone, $B: H \rightarrow 2^{H}$ maximal monotone, $G: H \rightarrow H$-Lipschitz and $\eta$-strongly monotone, $\psi: H \rightarrow H$ L-Lipschitz, and $S: H \rightarrow H K$-strictly pseudocontractive. Define a mapping $T x:=(1-\sigma) x+\sigma S x$ for all $x \in H$. For arbitrarily given $x_{1} \in H$ and $\sigma \in[K, 1)$, let $\left\{x_{n}\right\}$ be the sequence generated iteratively by

$$
\begin{array}{r}
x_{n+1}=\alpha_{n} \gamma \psi\left(x_{n}\right)+\left(I-\alpha_{n} \mu G\right) T J_{r_{n}}\left(x_{n}-r_{n}\left(A x_{n}+a_{n}\right)\right), \\
\forall n \geq 1 .
\end{array}
$$

Assume that $\left\{\alpha_{n}\right\} \subset[0,1],\left\{r_{n}\right\} \subset(0,+\infty)$, and $\left\{a_{n}\right\} \subset H$ satisfying the following conditions:

(i) $\sum_{n=1}^{\infty}\left\|a_{n}\right\|<\infty$,

(ii) $\sum_{n=1}^{\infty} \alpha_{n}=\infty, \lim _{n \rightarrow \infty} \alpha_{n}=0$ and $\sum_{n=1}^{\infty}\left|\alpha_{n+1}-\alpha_{n}\right|<$ $\infty$,

(iii) $0<\liminf _{n \rightarrow \infty} r_{n} \leq \limsup _{n \rightarrow \infty} r_{n}<2 \alpha$ and $\sum_{n=1}^{\infty}$ $\left|r_{n+1}-r_{n}\right|<\infty$. 
Suppose in addition that $F(S) \cap(A+B)^{-1}(0) \neq \emptyset, 0<\mu<2 \eta / k^{2}$ and $0 \leq \gamma L<\tau$, where $\tau=\mu\left(\eta-\mu k^{2} / 2\right)$. Then $\left\{x_{n}\right\}$ converges strongly to some point $z \in F(S) \cap(A+B)^{-1}(0)$ which solves the variational inequality: $\langle\gamma \psi(z)-\mu G(z), x-z\rangle \leq 0$, for all $x \in F(S) \cap(A+B)^{-1}(0)$.

\section{Applications}

Using Corollary 24, we consider the problem for finding a common element of the set of solutions of a mathematical model related to equilibrium problems and the set of fixed points of a strict pseudocontraction in a Hilbert space. Let $C$ be a nonempty, closed, and convex subset of a Hilbert space and let $f: C \times C \rightarrow \mathbb{R}$ be a bifunction satisfying the following conditions:

(A1) $f(x, x)=0$ for all $x \in C$;

(A2) $f$ is monotone, that is, $f(x, y)+f(y, x) \leq 0$ for all $x, y \in C$;

(A3) for all $x, y, z \in C$,

$$
\limsup _{t \downarrow 0} f(t z+(1-t) x, y) \leq f(x, y)
$$

(A4) for all $x \in C, f(x, \cdot)$ is convex and lower semicontinuous.

Then, the mathematical model related to equilibrium problems (with respect to $C$ ) is to find $\widehat{x} \in C$ such that

$$
f(\widehat{x}, y)=0
$$

for all $y \in C$. The set of such solutions $\widehat{x}$ is denoted by $\operatorname{EP}(f)$.

The following lemma appears implicitly in Blum and Oettli [26].

Lemma 25. Let $C$ be a nonempty, closed, and convex subset of $H$ and let $f: C \times C \rightarrow \mathbb{R}$ be a bifunction satisfying (A1)-(A4). Let $r>0$ and $x \in H$. Then, there exists $z \in C$ such that

$$
f(z, y)+\frac{1}{r}\langle y-z, z-x\rangle \geq 0, \quad \forall y \in C .
$$

The following lemma was also given in Combettes and Hirstoaga [27].

Lemma 26. Assume that $f: C \times C \rightarrow \mathbb{R}$ satisfies (A1)-(A4). For $r>0$ and $x \in H$, define a mapping $S_{r}: H \rightarrow C$ as follows:

$$
S_{r} x=\left\{z \in C: f(z, y)+\frac{1}{r}\langle y-z, z-x\rangle \geq 0, \forall y \in C\right\}
$$

for all $x \in H$. Then, the following hold:

(1) $S_{r}$ is single-valued;

(2) $S_{r}$ is a firmly nonexpansive mapping; that is, for all $x, y \in H,\left\|S_{r} x-S_{r} y\right\|^{2} \leq\left\langle S_{r} x-S_{r} y, x-y\right\rangle ;$

(3) $F\left(S_{r}\right)=E P(f)$;

(4) $E P(f)$ is closed and convex.
We call such $S_{r}$ the resolvent of $f$ for $r>0$. Using Lemmas 25 and 26, Takahashi et al. [10] proved the following theorem. See [10] for a more general result.

Theorem 27. Let $H$ be a Hilbert space and let $C$ be a nonempty, closed, and convex subset of $H$. Let $f: C \times C \rightarrow \mathbb{R}$ satisfy (A1)-(A4). Let $A_{f}$ be a multivalued mapping of $H$ into itself defined by

$$
A_{f} x=\left\{\begin{array}{r}
\{z \in H: f(x, y) \geq\langle y-x, z\rangle, \\
\emptyset, \quad x \notin C . C\}, \quad x \in C,
\end{array}\right.
$$

Then, $E P(f)=A_{f}^{-1} 0$ and $A_{f}$ is a maximal monotone operator with $\operatorname{dom}\left(A_{f}\right) \subset C$. Further, for any $x \in H$ and $r>0$, the resolvent $S_{r}$ of $f$ coincides with the resolvent of $A_{f}$; that is, $S_{r} x=\left(I+r A_{f}\right)^{-1} x$.

Theorem 28. Let $H$ be a real Hilbert space. Suppose $f: H \times$ $H \rightarrow \mathbb{R}$ is a bifunction satisfying the following conditions:

(B1) $f(x, x)=0$ for all $x \in H$;

(B2) $f$ is monotone, that is, $f(x, y)+f(y, x) \leq 0$ for all $x, y \in H$;

(B3) for all $x, y, z \in H$,

$$
\limsup _{t \downarrow 0} f(t z+(1-t) x, y) \leq f(x, y)
$$

(B4) for all $x \in H, f(x, \cdot)$ is convex and lower semicontinuous. Assume $S_{\delta}$ is the resolvent of $f$ for $\delta>0, G$ : $H \rightarrow H$ is $k$-Lipschitz and $\eta$-strongly monotone, $\psi: H \rightarrow H$ is L-Lipschitz, and $S: H \rightarrow H$ is $K$-strictly pseudocontractive. Define a mapping Tx := $(1-\sigma) x+\sigma S x$ for all $x \in H$. For arbitrarily given $x_{1} \in H$ and $\sigma \in[K, 1)$, let $\left\{x_{n}\right\}$ be the sequence generated iteratively by

$$
x_{n+1}=\alpha_{n} \gamma \psi\left(x_{n}\right)+\left(I-\alpha_{n} \mu G\right) T S_{r_{n}} x_{n}, \quad \forall n \geq 1 .
$$

Assume that $\left\{\alpha_{n}\right\} \subset[0,1]$ and $\left\{r_{n}\right\} \subset(0,+\infty)$ satisfying the following conditions:

(i) $\sum_{n=1}^{\infty} \alpha_{n}=\infty, \lim _{n \rightarrow \infty} \alpha_{n}=0$ and $\sum_{n=1}^{\infty}\left|\alpha_{n+1}-\alpha_{n}\right|<$ $\infty$,

(ii) $\sum_{n=1}^{\infty}\left|r_{n+1}-r_{n}\right|<\infty$.

Suppose in addition that $F(S) \cap E P(f) \neq \emptyset, 0<\mu<2 \eta / k^{2}$ and $0 \leq \gamma L<\tau$, where $\tau=\mu\left(\eta-\mu k^{2} / 2\right)$. Then $\left\{x_{n}\right\}$ converges strongly to some point $z \in F(S) \cap E P(f)$ which solves the variational inequality: $\langle\gamma \psi(z)-\mu G(z), x-z\rangle \leq 0$, for all $x \in F(S) \cap E P(f)$.

Proof. Put $A=0$ and $a_{n}=0$ for all $n \in \mathbb{N}$ in Corollary 24 . From Theorem 27, we also know that $J_{r_{n}}^{A_{f}}=S_{r_{n}}$ for all $n \in \mathbb{N}$. So, we obtain the desired result by Corollary 24 .

\section{Conflict of Interests}

The authors declare that they have no competing interests. 


\section{Acknowledgments}

The work of L. C. Ceng was partially supported by the National Science Foundation of China (11071169), Ph.D. Program Foundation of Ministry of Education of China (20123127110002).

\section{References}

[1] F. E. Browder and W. V. Petryshyn, "Construction of fixed points of nonlinear mappings in Hilbert space," Journal of Mathematical Analysis and Applications, vol. 20, no. 2, pp. 197228, 1967.

[2] M. A. Noor and K. I. Noor, "Sensitivity analysis for quasivariational inclusions," Journal of Mathematical Analysis and Applications, vol. 236, no. 2, pp. 290-299, 1999.

[3] V. F. Demyanov, G. E. Stavroulakis, L. N. Polyakova, and P. D. Panagiotopoulos, Quasidifferentiability and Nonsmooth Modelling in Mechanics, Engineering and Economics, vol. 10, Kluwer Academic, Dordrecht, The Netherlands, 1996.

[4] S. Kamimura and W. Takahashi, "Approximating solutions of maximal monotone operators in Hilbert spaces," Journal of Approximation Theory, vol. 106, no. 2, pp. 226-240, 2000.

[5] Y. Yao, Y. J. Cho, and Y.-C. Liou, "Algorithms of common solutions for variational inclusions, mixed equilibrium problems and fixed point problems," European Journal of Operational Research, vol. 212, no. 2, pp. 242-250, 2011.

[6] M. A. Noor, "Generalized set-valued variational inclusions and resolvent equations," Journal of Mathematical Analysis and Applications, vol. 228, no. 1, pp. 206-220, 1998.

[7] P. Hartman and G. Stampacchia, "On some non-linear elliptic differential-functional equations," Acta Mathematica, vol. 115, no. 1, pp. 271-310, 1966.

[8] S.-S. Zhang, J. H. W. Lee, and C. K. Chan, "Algorithms of common solutions to quasi variational inclusion and fixed point problems," Applied Mathematics and Mechanics, vol. 29, no. 5, pp. 571-581, 2008.

[9] H. Manaka and W. Takahashi, "Weak convergence theorems for maximal monotone operators with nonspreading mappings in a Hilbert space," Cubo, vol. 13, no. 1, pp. 11-24, 2011.

[10] S. Takahashi, W. Takahashi, and M. Toyoda, "Strong convergence theorems for maximal monotone operators with nonlinear mappings in Hilbert spaces," Journal of Optimization Theory and Applications, vol. 147, no. 1, pp. 27-41, 2010.

[11] K. Aoyama, H. Iiduka, and W. Takahashi, "Weak convergence of an iterative sequence for accretive operators in Banach spaces," Fixed Point Theory and Applications, vol. 2006, Article ID 35390, 13 pages, 2006.

[12] H. Zegeye and N. Shahzad, "Strong convergence theorems for a common zero of a finite family of $m$-accretive mappings," Nonlinear Analysis: Theory, Methods \& Applications, vol. 66, no. 5, pp. 1161-1169, 2007.

[13] J.-M. Chen and T.-G. Fan, "Viscosity approximation methods for two accretive operators in Banach spaces," Abstract and Applied Analysis, vol. 2013, Article ID 670523, 9 pages, 2013.

[14] G. López, V. Martín-Márquez, F. Wang, and H.-K. Xu, "Forward-backward splitting methods for accretive operators in Banach spaces," Abstract and Applied Analysis, vol. 2012, Article ID 109236, 25 pages, 2012.

[15] S. Y. Cho, X. L. Qin, and L. Wang, "Iterative algorithms with errors for zero points of $m$-accretive operators," Fixed Point Theory and Applications, vol. 2013, article 148, 2013.
[16] H. Y. Zhou, "Convergence theorems for $\lambda$-strict pseudocontractions in q-uniformly smooth Banach spaces," Acta Mathematica Sinica, vol. 26, no. 4, pp. 743-758, 2010.

[17] P. Sunthrayuth and P. Kumam, "Iterative methods for variational inequality problems and fixed point problems of a countable family of strict pseudo-contractions in a $q$-uniformly smooth Banach space," Fixed Point Theory and Applications, vol. 2012, article 65, 2012.

[18] O. Scherzer, "Convergence criteria of iterative methods based on Landweber iteration for solving nonlinear problems," Journal of Mathematical Analysis and Applications, vol. 194, no. 3, pp. 911-933, 1995.

[19] H.-K. Xu, "Inequalities in Banach spaces with applications," Nonlinear Analysis: Theory, Methods \& Applications, vol. 16, no. 12, pp. 1127-1138, 1991.

[20] K. K. Tan and H. K. Xu, "Approximating fixed points of nonexpansive mappings by the Ishikawa iteration process," Journal of Mathematical Analysis and Applications, vol. 178, no. 2, pp. 301-308, 1993.

[21] K. Aoyama, Y. Kimura, W. Takahashi, and M. Toyoda, "Approximation of common fixed points of a countable family of nonexpansive mappings in a Banach space," Nonlinear Analysis: Theory, Methods \& Applications, vol. 67, no. 8, pp. 2350-2360, 2007.

[22] F. E. Browder, "Semicontractive and semiaccretive nonlinear mappings in Banach spaces," Bulletin of the American Mathematical Society, vol. 74, pp. 660-665, 1968.

[23] R. E. Bruck, "A simple proof of the mean ergodic theorem for nonlinear contractions in Banach spaces," Israel Journal of Mathematics, vol. 32, no. 2-3, pp. 107-116, 1979.

[24] W. Kaczor, "Weak convergence of almost orbits of asymptotically nonexpansive commutative semigroups," Journal of Mathematical Analysis and Applications, vol. 272, no. 2, pp. 565$574,2002$.

[25] Y. Song and L. Ceng, "A general iteration scheme for variational inequality problem and common fixed point problems of nonexpansive mappings in q-uniformly smooth Banach spaces," Journal of Global Optimization, vol. 57, no. 4, pp. 1327-1348, 2013.

[26] E. Blum and W. Oettli, "From optimization and variational inequalities to equilibrium problems," The Mathematics Student, vol. 63, no. 1-4, pp. 123-145, 1994.

[27] P. L. Combettes and S. A. Hirstoaga, "Equilibrium programming in Hilbert spaces," Journal of Nonlinear and Convex Analysis, vol. 6, no. 1, pp. 117-136, 2005. 


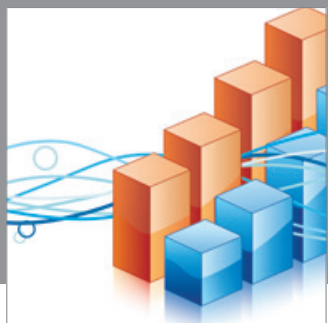

Advances in

Operations Research

mansans

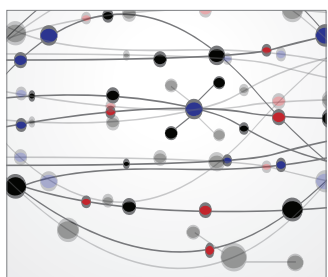

The Scientific World Journal
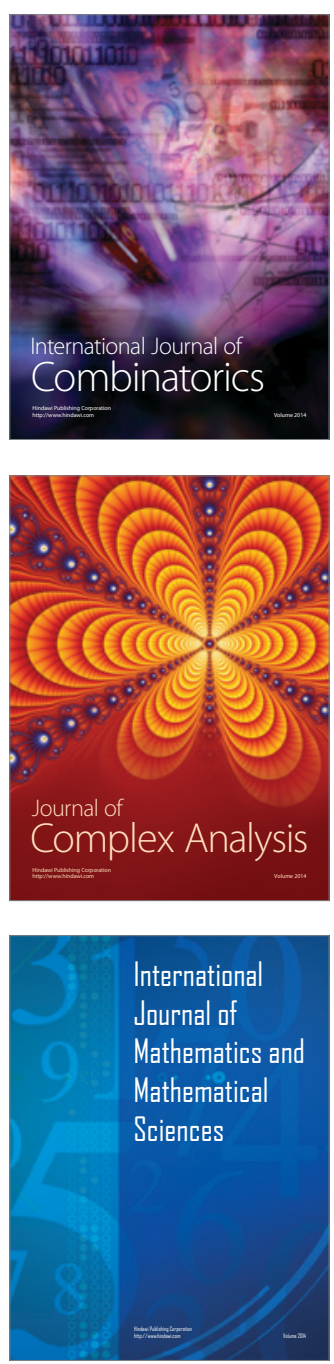
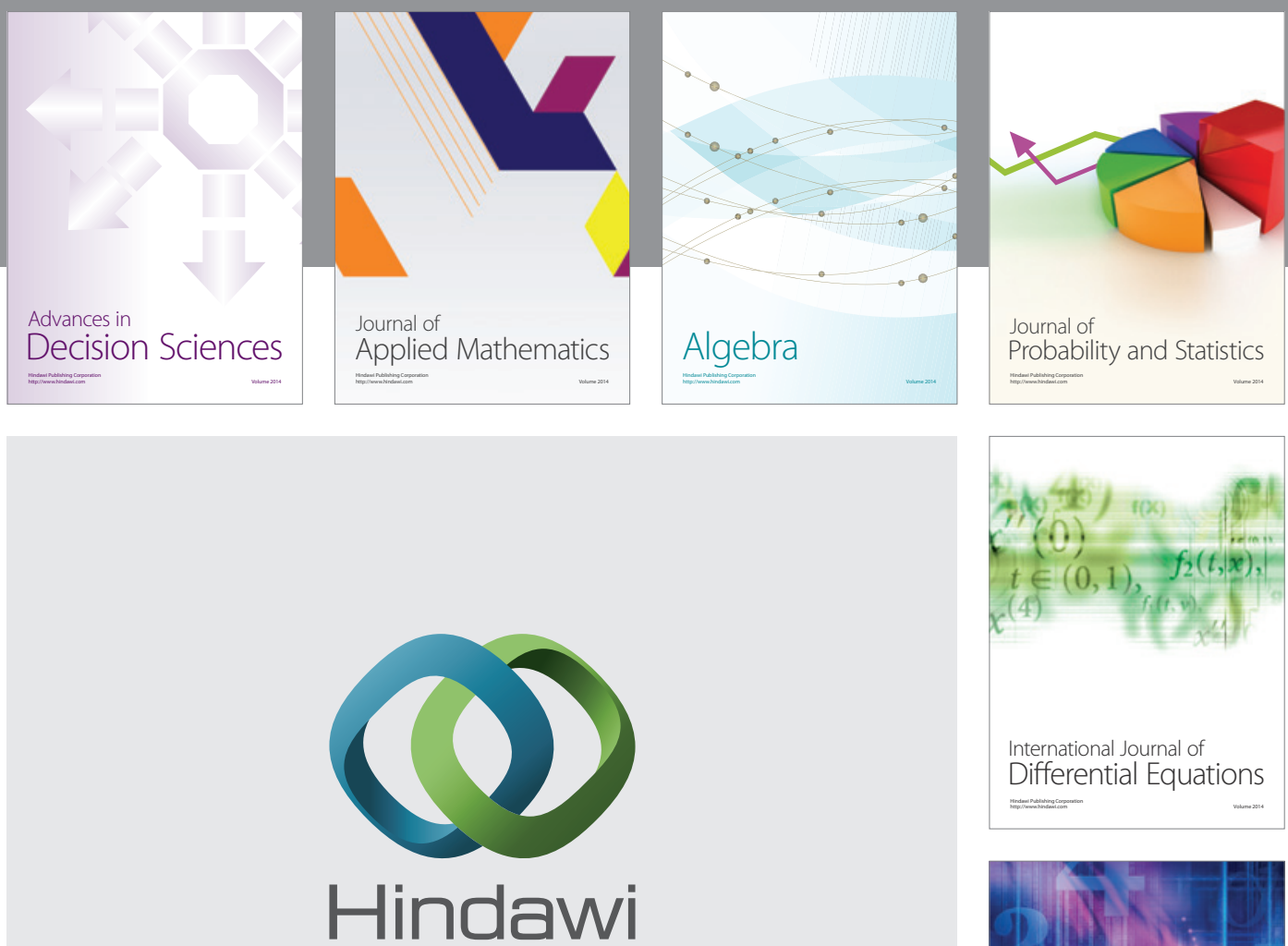

Submit your manuscripts at http://www.hindawi.com
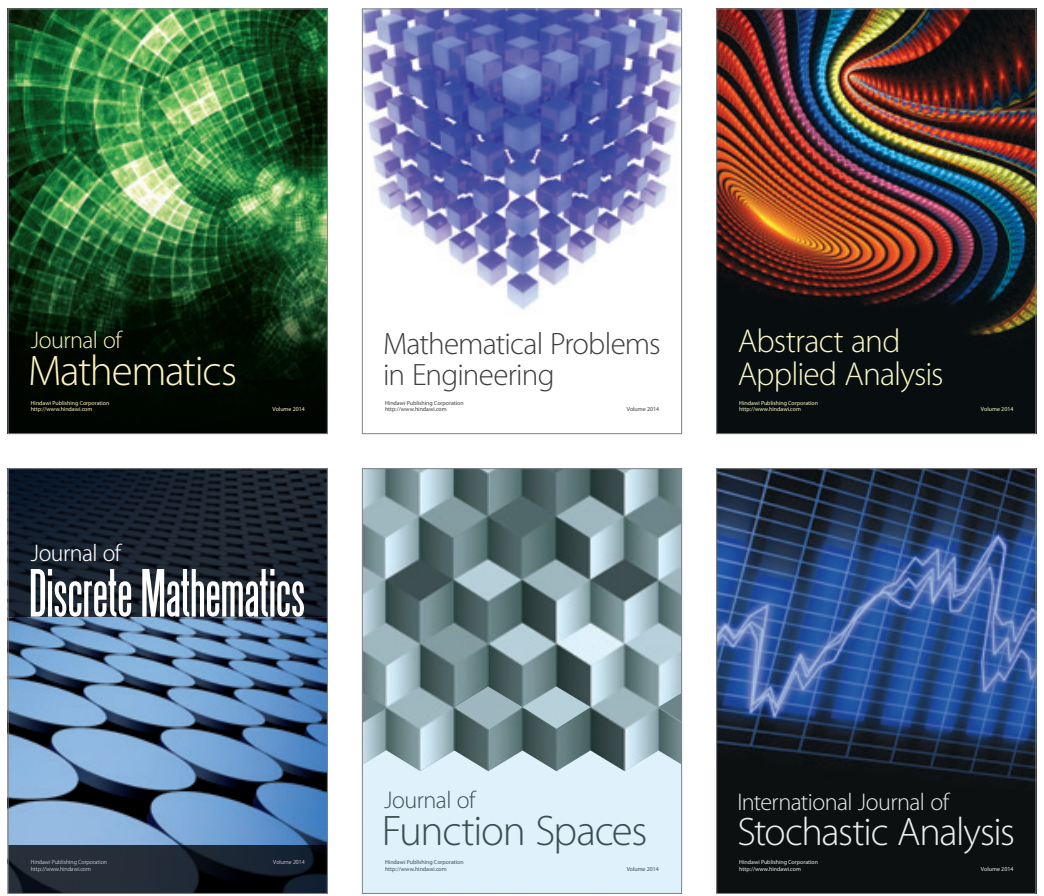

Journal of

Function Spaces

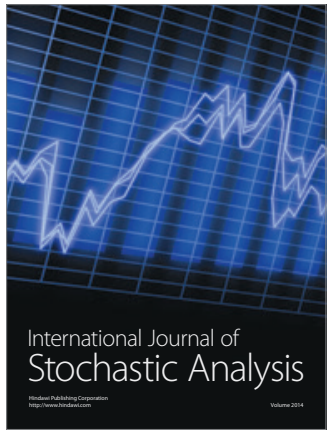

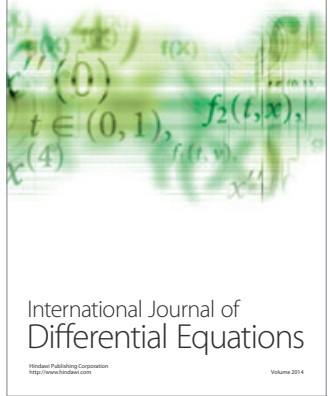
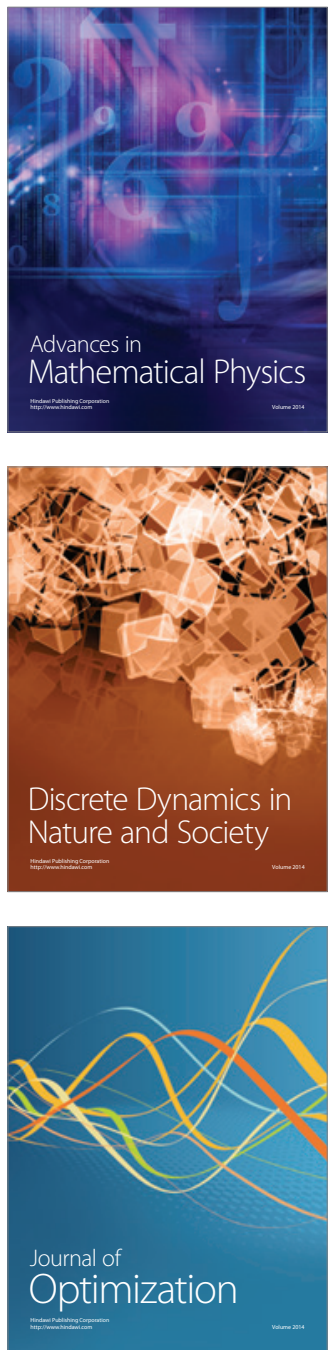